\title{
Effect of dietary L-tryptophan on cannibalism, survival and growth in pikeperch Sander lucioperca (L.) post-larvae
}

\author{
Jarosław Król ${ }^{1} \cdot$ Zdzisław Zakęś $^{2}$
}

Received: 20 November 2014 / Accepted: 29 July 2015/Published online: 5 August 2015

(C) The Author(s) 2015. This article is published with open access at Springerlink.com

\begin{abstract}
The effect of supplemented commercial diets with crystalline L-tryptophan (TRP5,10 and $20 \mathrm{~g} \mathrm{TRP} \mathrm{kg}^{-1}$ ) on cannibalism, survival and growth parameters of pikeperch postlarvae (Sander lucioperca) was evaluated. Fifteen-day-old pikeperch larvae (mean weight$6.8 \mathrm{mg}$ ) were reared during the next 28 days $\left(20.5^{\circ} \mathrm{C}, 16 \mathrm{~L}: 8 \mathrm{D}\right)$ in glass aquaria in a recirculating aquaculture system. The enzyme-linked immunosorbent assay showed that TRP-supplemented diets were effective in increasing the levels of serotonin (5-HT) in the body tissue of pikeperch. TRP supplementation resulted in a slight decrease in both types of cannibalism, although the reduction in cannibalism impact did not amount to more than a few percent. TRP treatment had no significant influence on the final survival of pikeperch post-larvae (ranged from $20.1 \pm 12.4$ to $29.0 \pm 12.9 \%$ ). However, contrary to the earlier studies conducted on other fish species, no significant difference in the growth rates and feeding behavior of pikeperch between TRP-fed and control group were found. The final body weight and growth rate ranged from $0.211 \pm 0.014$ to $0.243 \pm 0.016$ and from $12.19 \pm 0.38$ to $12.76 \pm 0.35 \%$ day $^{-1}$, respectively. To our knowledge, this is the first study reporting the effects of TRP supplementation on the cannibalism-survival-growth relations in fish in the post-larval stage.
\end{abstract}

Keywords Cannibalism · Growth · Pikeperch · Post-larvae $\cdot$ Tryptophan · Survival

\section{Introduction}

The fast growth and good nutritional value of the meat have contributed to the increase in interest in aquaculture of European percid fish species. Pikeperch (Sander lucioperca) is considered among the most promising species for possible intensive fish farming in Europe

Jarosław Król

krolas@uwm.edu.pl

1 Department of Ichthyology, University of Warmia and Mazury in Olsztyn, Al. Warszawska 117A, 10-719 Olsztyn, Poland

2 Department of Aquaculture, Stanisław Sakowicz Inland Fisheries Institute in Olsztyn, Olsztyn, Poland 
(Kestemont and Mélard 2000; Teletchea and Fontaine 2014). In the last decade, methods for pikeperch reproduction in controlled conditions have been increased substantially (review Zakęś and Demska-Zakęś 2009). The key to the further development of the production of the pikeperch is to optimize conditions for rearing both, the larval and the juvenile stages. In farmed percid fish species, intra-cohort cannibalism, besides swim bladder inflation and non-feeding behavior, is an important factor that affects survival, especially during the early life stages of fish (Baras et al. 2003; Kestemont et al. 2003; Babiak et al. 2004; Hamza et al. 2007; Kestemont et al. 2007; Mandiki et al. 2007; Szkudlarek and Zakęś 2007; Król et al. 2015). Cannibalism is intra-specific predation. The cannibal kills and consumes the entire or major part of a conspecific individual. This behavior is widespread in farmed teleosts, and the occurrence of cannibalism has been identified in at least 36 families (Smith and Reay 1991). Intra-cohort cannibalism is mainly caused by size heterogeneity of larvae, which is usually affected by multiple interactive and non-interactive factors such as the environment and population structure, respectively (Kestemont et al. 2003). During the first days of life, when the size dispersal of larvae is low, type I cannibalism (incomplete-biting the abdomen or tail) occurs. Later, as size heterogeneity increases, type I cannibalism is replaced by type II cannibalism (complete—total prey ingestion) (Cuff 1980; Hecht and Appelbaum 1988; Hecht and Pienaar 1993; Baras and Jobling 2002; Baras et al. 2003). Beside several population factors (density and size heterogeneity) as well as extrinsic factors (environmental structure, temperature, and light intensity) that regulate cannibalism in fish larvae, food availability and quality are the most decisive factors which can account for the emergence and intensity of cannibalism (Hecht and Appelbaum 1988; Hecht and Pienaar 1993; Baras and Jobling 2002; Baras 2013). The complete elimination of cannibalism in the cohort of percid larvae is probably impossible, and to date, attempts to mitigate cannibalism have mainly focused on routine size-grading and using procedures based on both extrinsic and intrinsic factors or food quantity and quality, with special emphasis on weaning protocols (Kestemont et al. 2003, 2007; Szczepkowski et al. 2011). Dietary factors could be an alternative method for limiting cannibalistic behavior in the cohort of fish larvae. Tryptophan (TRP) is the precursor of serotonin $(5-\mathrm{HT})$, which is known to reduce aggression in vertebrates (including fish; Hseu et al. 2003; Höglund et al. 2005) and also in farmed aquatic invertebrates (e.g., crabs and crayfish; Laranja et al. 2010; Harlioğlu et al. 2014). Supplemented TRP in the feed enhances production of serotonin in the fish brain and usually increases resisting stress (Johnston et al. 1990; Winberg et al. 2001; Lepage et al. 2002) or decreases aggressive behavior (Winberg et al. 2001; Hseu et al. 2003; Höglund et al. 2005). However, feeding the fish tryptophan-supplemented diet contributed to increasing levels of serotonin which tend to limit food intake and thereby resulted in depressed fish growth (De Pedro et al. 1998; Hseu et al. 2003; Papoutsoglou et al. 2005a).

Based on those findings, the purpose of this study was to investigate the potential effect of dietary tryptophan supplementation on cannibalism, survival and growth of pikeperch post-larvae.

\section{Materials and methods}

\section{Experimental larvae}

The study material was obtained from pikeperch spawners held in recirculating aquaculture systems (RAS) in the Department of Aquaculture of the Inland Fisheries Institute in Olsztyn. The pikeperch larvae were obtained and reared before the experimental period in 
accordance with previously established procedures (Zakęś 2007; Szkudlarek and Zakęś 2007).

\section{Diet preparation}

Two commercial diets, Perla Larva Proactive 5.0 and 4.0 (Trouvit Nutreco Holland) were used for preparing the experimental diets (T1, T2 and T3) and as the control diet (T0). Formulated diets contained $62 \%$ protein, $11 \%$ lipid, $10 \%$ carbohydrates and $0.69 \%$ tryptophan (1.12\% of dietary protein). Supplemented diets were prepared by the sprinkle method, containing $5 \mathrm{~g} \mathrm{TRP} \mathrm{kg}^{-1}$ (T1-1.19\% TRP; $1.93 \%$ of dietary protein), $10 \mathrm{~g}$ TRP kg ${ }^{-1}$ (T2-1.69 \% TRP; $2.74 \%$ of dietary protein) and $20 \mathrm{~g} \mathrm{TRP} \mathrm{kg}^{-1}$ (T3-2.69\% TRP; $4.36 \%$ of dietary protein). The TRP (crystalline L-tryptophan, Sigma, USA) of each treatment was weighed, dissolved in hot water plus ethanol, then sprinkled on the commercial diet and vaporized using a vacuum chamber (AGA Labor, Lublin, Poland). The diets were dried at room temperature and stored at $4{ }^{\circ} \mathrm{C}$ before feeding. To avoid the palatability effect, T0 was sprinkled with ethanol solution without addition of tryptophan.

\section{Experimental design, data collection and analysis}

Before the experiment, 30 pikeperch larvae were killed by using an overdose of anesthetic (2phenoxyethanol-2 $\mathrm{mL} \mathrm{L}^{-1}$ ) then individually weighed (nearest to $0.0001 \mathrm{~g}$ ) and measured (nearest to $0.01 \mathrm{~cm}$ ). Fifteen-day-old larvae (with swim bladder inflation-ISBI at $83.3 \%$ ) were randomly divided in four groups, consisting of three replications, and fed on commercial diets without TRP (T0 — control group) or with TRP (5 $\mathrm{g} \mathrm{kg}^{-1}-\mathrm{T} 1$ group, $10 \mathrm{~g} \mathrm{~kg}^{-1}$ - T2 group, and $20 \mathrm{~g} \mathrm{~kg}^{-1}$ - T3 group). The fish were reared for 28 days in a recirculating aquaculture system consisting of 12 rectangle glass aquaria with a volume of $30 \mathrm{~L}$ each. Each aquarium was stocked with 450 larvae (with the density of 15 larvae $\mathrm{L}^{-1}$ ). The recirculating system was equipped with UV lamp, a lamellar filter for mechanical water purification and a trickling filter for biological water purification. The daily water exchange amounted to $10 \%$ of the total unit volume $\left(1.5 \mathrm{~m}^{3}\right)$. The water flow through the rearing aquaria was increased gradually as the larvae grew from 1.2 to $2.0 \mathrm{~L} \mathrm{~min}^{-1}$. The fish were exposed to a 16-h-light and 8-h-dark photoperiods, and the light intensity measured just above the water surface in the rearing aquaria ranged from 60 to $75 \mathrm{~lx}$. The water temperature and dissolved oxygen were measured daily and totaled, on average, $20.5 \pm 0.5{ }^{\circ} \mathrm{C}$ and $7.2 \pm 0.6 \mathrm{mg} \mathrm{L}^{-1}$, respectively. Nitrogenous compounds were measured twice a week and did not exceed 0.1 and $0.05 \mathrm{mg} \mathrm{L}^{-1}$ for $\mathrm{N}-\mathrm{NH}_{4}{ }^{+}$and $\mathrm{N}-\mathrm{NO}_{2}{ }^{-}$, respectively. Before the experiment, from 5 to 14 days after hatching, the pikeperch larvae were fed in excess by hand with mixed feed (Artemia nauplii and commercial diet-Perla Larva Proactive 5.0) six times a day (8:00, 10:00, 12:00, 14:00, 17:00 and 20:00). Throughout the experiment, the fish were exclusively fed with Perla Larva Proactive 5.0 for the first 10 days of the experiment, and then they were gradually switched to Perla Larva Proactive 4.0. During the entire experiment, the fish were fed ad libitum six times a day at the same hours as before. The rearing aquaria were cleaned of unconsumed food and fish waste once daily in the morning before feeding. Dead fish were removed daily and ranked as truncated (the posterior damaged or tailed-off) or non-truncated (starving, intact or with traces of bites on the abdomen or head) using Stereo Microscope LEICA MZ16A with Qwin Pro software. Truncated individuals were considered as victims of type I cannibalism and non-truncated fish as deaths by other causes. Bitten abdomens or heads are typical secondary postmortem damages in farmed percids; therefore, individuals having such damages were not classified as type I cannibalism 
victims (Baras et al. 2003; Babiak et al. 2004). At the end of the experiment, all survivors per tank were counted, and 30 fish per tank were weighed (nearest to $0.001 \mathrm{~g}$ ) and measured (nearest to $0.01 \mathrm{~cm}$ ). Missing fish were considered as victims of type II cannibalism $\left[(\%)=100 \mathrm{INF}-(\mathrm{FNF}+\mathrm{DF}) \mathrm{INF}^{-1}\right.$, where INF $=$ initial number of fish, $\mathrm{FNF}=$ final number of fish, $\mathrm{DF}=$ number of truncated and non-truncated death fish]. Potential cannibals [fish with FBW three times higher than the average FBW; $(\%)=100 \mathrm{NC} \mathrm{FNF}^{-1}$, where $\mathrm{NC}=$ number of potential cannibals, $\mathrm{FNF}=$ final number of fish] in each aquarium separately were also counted and weighed. Coefficients of variation in body weight [CV $(\%)=100 \times \mathrm{SDBW} \times \mathrm{BW}^{-1}$, where $\mathrm{BW}=$ average body weight and SDBW $=$ standard deviation of body weight] were calculated for the first and the last day of the experiment $\left(\mathrm{CV}_{\mathrm{IBW}}\right.$ and $\mathrm{CV}_{\mathrm{FBW}}$, respectively). At the same time, condition factor $\left[\mathrm{F}=100 \mathrm{BW} \mathrm{BL}^{-3}\right.$, where $\mathrm{BW}=$ average body weight and $\mathrm{BL}=$ average body length] was calculated $\left(\mathrm{F}_{\mathrm{I}}\right.$ and $\mathrm{F}_{\mathrm{F}}$, respectively). Overall specific growth rates $\left[\operatorname{SGR}\left(\%\right.\right.$ day $\left.^{-1}\right)=100 \times(\mathrm{Ln} \mathrm{FBW}-\mathrm{Ln}$ IBW) $\times t^{-1}$, where FBW = average final body weight and IBW $=$ average initial body weight $(\mathrm{g}) ; t=28$ days] were also calculated $\left(\mathrm{SGR}_{0-28}\right) . \mathrm{CV}_{\mathrm{FBW}}, \mathrm{F}$ and $\mathrm{SGR}_{0-28}$ were calculated based on weights of 30 fish in each tank without potential cannibals.

\section{Determination of serotonin (5-HT) levels}

At the end of experiment, 15 fish from each group were killed (anesthetic overdose), than separately maintained in an Eppendorf tube [containing $1 \%$ sodium citrate as anticoagulant (1:1) and $1 \%$ ascorbic acid solution] and stored at $-80{ }^{\circ} \mathrm{C}$ until needed. Because of small fish size $(<0.3 \mathrm{~g}$ body weight), whole fish were used for estimation of serotonin levels. Briefly after thawing, fish were homogenized with PBS buffer ( $\mathrm{pH} 7.2)$ and tissue homogenates were centrifuged twice at $10,000 \times g$ for $2 \mathrm{~min}$ at $4{ }^{\circ} \mathrm{C}$. The supernatant was removed and used for the 5-HT determination by enzyme-linked immunosorbent assay (ELISA) according to kit instruction (IBL, Hamburg, Germany).

\section{Statistical analysis}

Growth parameters, all mortality type and survival were compared using one-way ANOVA. Normality of parameters distribution was tested by Kolmogorov-Smirnov test. The data expressed in percentages were Arcsine-transformed prior to the statistical analysis. Significance of differences between groups was estimated using a post hoc Duncan's multiple range test. For CV and potential cannibals (\%) values, a nonparametric KruskalWallis test was used. Multiple regression analysis was used to estimate relationships between both cannibalism types, number of potential cannibals and survival ( $r=$ standardized regression coefficient and $F=$ value of Fisher's test). Null hypotheses were rejected at $P<0.05$. Analyses were performed using Statistica software (StatSoft).

\section{Results}

\section{Serotonin levels}

ELISA showed that TRP-supplemented diets were effective in increasing the levels of serotonin $(5-\mathrm{HT})$ production in the body of pikeperch. Serotonin concentration in fish tissues increased proportionally to the dose of TRP in the feed (Fig. 1). 


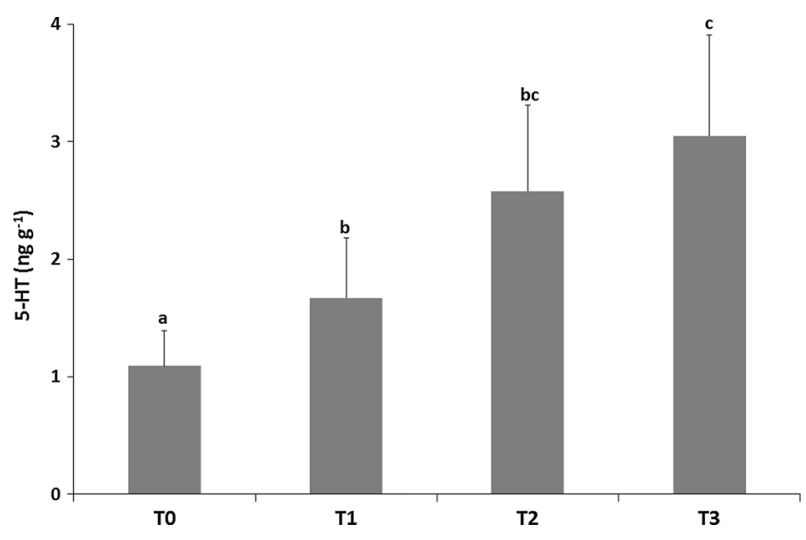

Fig. 1 Serotonin (5-HT) levels of pikeperch post-larvae fed feeds supplemented with tryptophan (T0, T1, T2 and T3) after 28 days of rearing. Bars and whiskers are the means and standard deviations of 15 fish per group. Values marked with different superscripts differ at $P<0.05$. Values are presented as ng $\mathrm{g}^{-1}$ of body weight

\section{Cannibalism and survival}

The intensity of type I cannibalism was affected by the TRP content, but exclusively during the first 8-14 days of the experiment, when the highest mortality was observed in group T0 (Figs. 2, 3). In the following days, this type of cannibalism was switched to complete cannibalism (type II). Type II cannibalism was not significantly affected by TRP content, but the highest mortality was also observed in group T0 (Fig. 3). Mortality caused by type II cannibalism significantly and negatively affected the final survival $(r=-0.89$; $F=41.21 ; P<0.05)$ contrary to mortality caused by type I which did not exert major impact on final survival $(P>0.05)$. Mortality due to other causes than cannibalism was relatively frequent, but did not differ among groups (Fig. 3). The average survival at the end of experiment did not differ among groups (Fig. 4). The number of cannibals was not

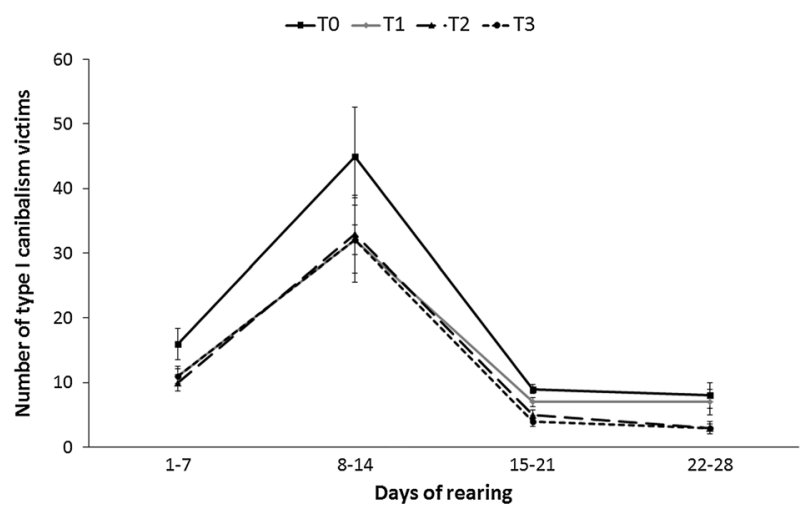

Fig. 2 Weekly dynamics of mortality caused by type I cannibalism in the experimental groups of pikeperch post-larvae fed feeds supplemented with Tryptophan (T0, T1, T2 and T3) 


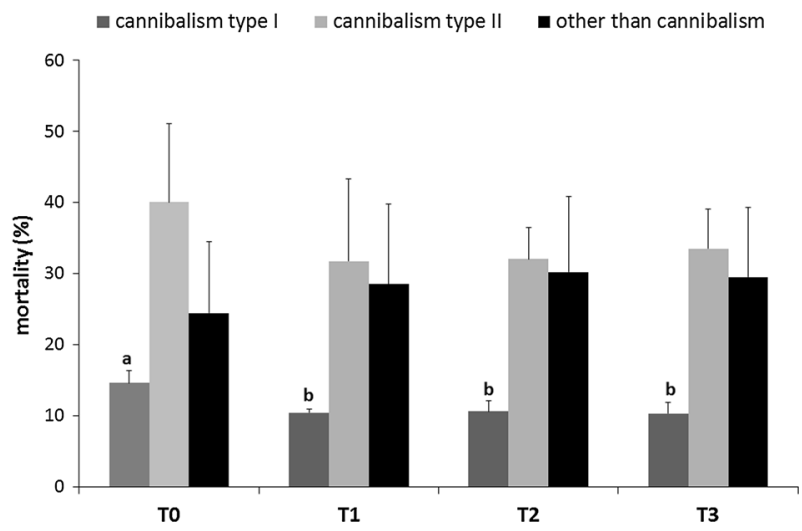

Fig. 3 Respective contributions of incomplete (type I) and complete (type II) cannibalism and mortality from other causes in pikeperch post-larvae fed feeds supplemented with tryptophan (T0, T1, T2 and T3) after 28 days of rearing. Bars and whiskers are the means and standard deviations of three replicates. Values marked with different superscripts differ at $P<0.05$

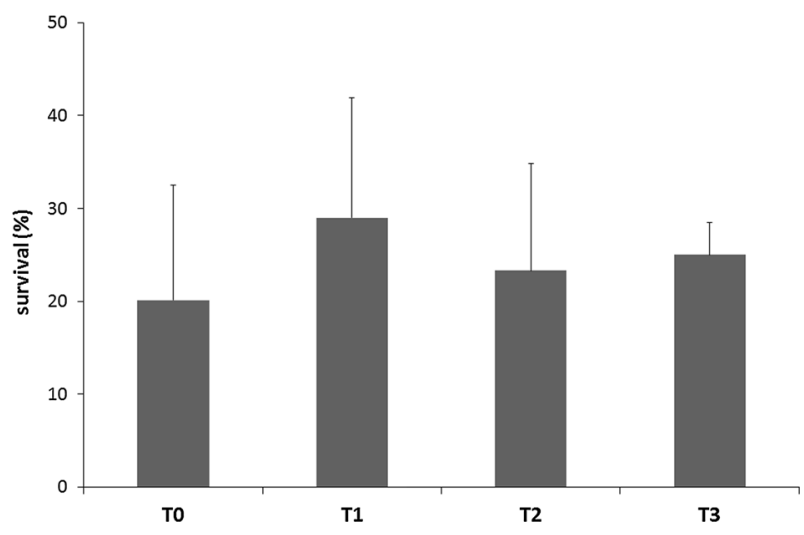

Fig. 4 Survival of pikeperch post-larvae fed feeds supplemented with tryptophan (T0, T1, T2 and T3) after 28 days of rearing. Bars and whiskers are the means and standard deviations of three replicates. No significant differences among groups were found $(P>0.05)$

affected by TRP content (Table 1), nonetheless significantly and negatively affected the final survival $(r=-0.71 ; F=10.33 ; P<0.05)$.

\section{Growth performance}

Over the entire experiment, body weight increased from $0.0068 \mathrm{~g}$ (IBW-day 0) to more than $0.28 \mathrm{~g}$ (FBW-day 28). The final body weight (FBW), final body length (FBL) and total specific growth rate $\left(\mathrm{SGR}_{0-28}\right)$ did not differ among all the experimental groups (Table 1). Fish indicated as potential cannibals were three times as heavy as conspecifics, irrespective of TRP treatments (Table 1). Coefficient of variation in FBW $\left(\mathrm{CV}_{\mathrm{FBW}}\right)$ remained at the same level as coefficient of variation in IBW $\left(\mathrm{CV}_{\mathrm{IBW}}\right)$ and did not differ among all the groups (Table 1). TRP treatment also had no significant effect on final 


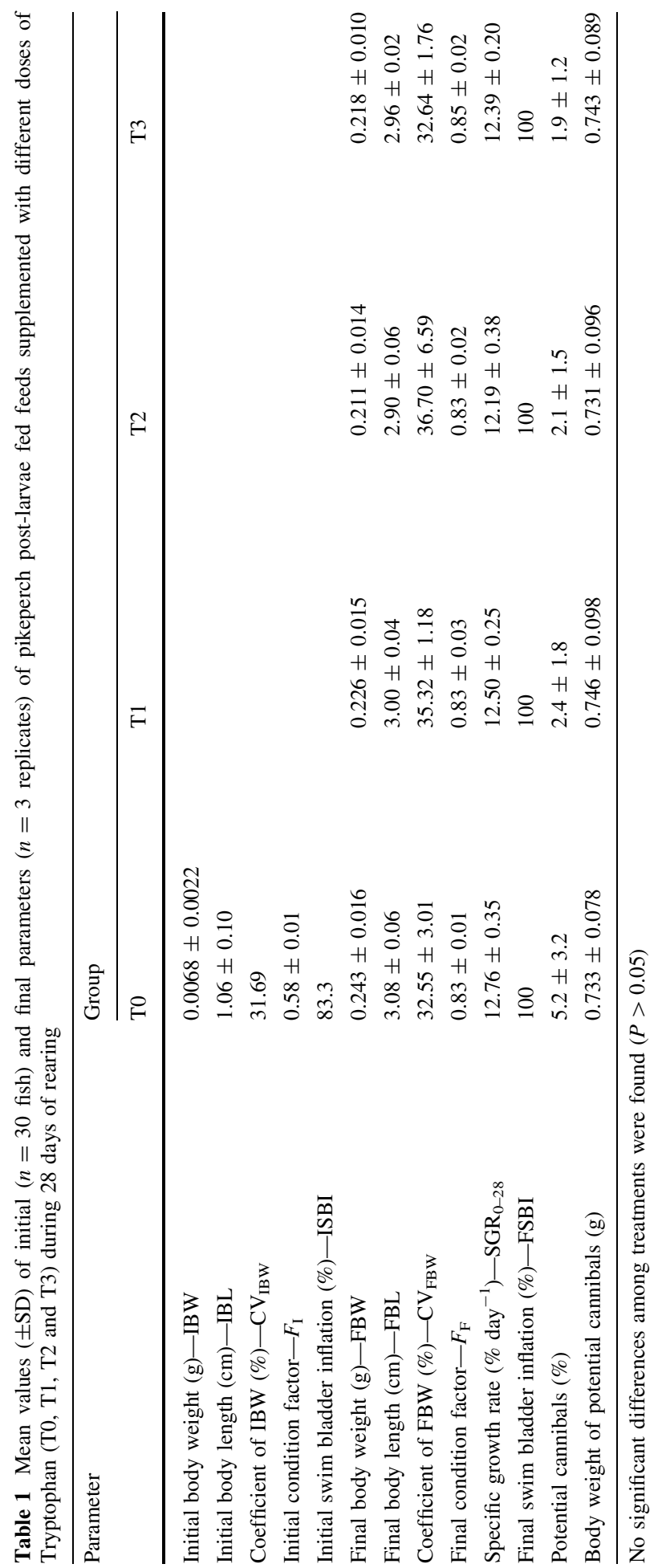


condition factor of the pikeperch $\left(F_{\mathrm{F}}\right.$, Table 1). At the end of experiment, all the fish checked (4 groups $\times 30$ fish) had inflated swim bladder $(\mathrm{FSBI}=100 \%$, Table 1$)$.

\section{Discussion}

\section{Effects TRP on cannibalism and survival}

The results of presently reported study confirmed that cannibalism was the main contributor to the mortality of pikeperch post-larvae, and the losses of type II cannibalism outnumbered those of type I cannibalism (Kestemont et al. 2007; Szkudlarek and Zakęś 2007; Szczepkowski et al. 2011). The difference between the respective contributions of type I and type II cannibalism here probably resulted due to the fact that our study started with larvae with incomplete inflated swim bladder $(83.3 \%)$ and thereby accelerated emergence of complete cannibalism. This occurs because percid larvae with non-inflated swim bladders are easy victims for cannibals due to the impairment of motor skills (Czesny et al. 2005; Szczepkowski et al. 2011). Moreover, early appearance of type II cannibalism could establish specific dominance hierarchy in the fish cohort and thereby limit the possibility of incomplete cannibalism. Duration and intensity of type II cannibalism are dependent on fish size distribution and the number of cannibals in the stocks (Baras and Jobling 2002), so it could be easily reduced by size sorting or elimination of cannibals from tanks (Szkudlarek and Zakęś 2007; Szczepkowski et al. 2011). In this study, during all of the experiment, potential cannibals were not removed from the aquaria, which could probably reduce losses caused by cannibalism. Besides, type II cannibalism is facilitated by growth advantage gained during type I cannibalism (Baras et al. 2003), so mitigation of early aggressive behavior (type I cannibalism) is more important for aquaculture of European percid fish species.

Optimization of feeding schedules in all nutritional aspects can minimize losses due to cannibalism in intensive fish farming (Kubitza and Lovshin 1999). Dietary supplementation of TRP has been shown to reduce aggressive behavior in several fish species, including the rainbow trout Oncorhynchus mykiss (Winberg et al. 2001), the orange-spotted grouper Epinephelus coioides (Hseu et al. 2003) and the Atlantic cod Gadus morhua (Höglund et al. 2005). The aforementioned studies suggested that effects of TRP on the reduction in aggressive behavior in fish originated from a higher brain 5-HT activity. However, no significant effect of TRP on hypothalamic 5-HT levels was detected, though suppressed aggressive behavior in the Amazonian characid Brycon amazonicus (Wolkers et al. 2014) were also found. The results of the present study showed that dietary supplementation with TRP suppressed aggressive behavior in post-larvae of pikeperch. Especially, type I cannibalism was significantly affected by the TRP treatment. Type II cannibalism was not significantly affected by TRP treatment, but slightly higher losses of fish were observed in the control group. TRP-supplemented diets were effective in increasing the levels of serotonin (5-HT) in the tissue of pikeperch, which supported the statement that effects of TRP on the reduction in cannibalism in fish originated from a higher brain 5-HT activity. However, in view of the rapid increases in TRP hydroxylase enzyme activity and in 5-HT concentration, mechanisms other than increased 5-HT biosynthesis may be involved in the control of aggression by TRP (Jacobs and Fornal 1991; Aldegunde et al. 2000; Wolkers et al. 2014).

In the present study, TRP treatments were ineffective in increasing the survival observed at the end of experiment, probably because mortality due to causes other than 
cannibalism was relatively frequent. High mortality (starving and non-truncated fish) probably resulted from too early weaning time (transition from live feed to dry feed) used here (15 days post-hatch). Pikeperch larvae should be weaned from 18 to 21 days posthatch, if they are fed mixed feed or later than 19 days post-hatch, if they are weaned without co-feeding procedure (Szkudlarek and Zakęś 2007; Kestemont et al. 2007). The relation between mortality and cannibalism in pikeperch larvae as the impact of weaning age was found, where the lowest mortality (48.1\%) and high cannibalism (36.7\%) were obtained in pikeperch weaned on day 19 post-hatch, whereas the highest mortality $(68.6 \%)$ and low cannibalism $(13.8 \%)$ were obtained in fish weaned on day 12 post-hatch (Kestemont et al. 2007). In the aforementioned study, final survival of the pikeperch was lower than in the present study and ranged from 17.7 to $15.3 \%$ for the ones weaned on day 12 post-hatch and on day 19 post-hatch, respectively. No significant effect of TRP supplementation on the survival in the orange-spotted grouper (Hseu et al. 2003) and European catfish Silurus glanis (Król et al. 2014) was found. Compared with survival obtained in the other, previous studies will be pointless because usually TRP effect on aggressive behavior was tested in juvenile fish (not in the larvae or post-larvae as here) or in non-obligate carnivores taxa, e.g., rainbow trout, and sometimes the aspect of survival was beyond the scope of these studies (Winberg et al. 2001; Höglund et al. 2005; Wolkers et al. 2014).

\section{Effects TRP on growth}

Effects of TRP supplementation on aggression and dominance hierarchies in fishes can also be mediated by variations in growth as high levels of serotonin tend to limit food intake and growth in fish (De Pedro et al. 1998; Hseu et al. 2003; Papoutsoglou et al. 2005a, b). These effects are expectedly higher in the larger fish, presumably the dominant ones, and in those which can consume a higher proportion of the feed offered (Winberg et al. 2001). Hseu et al. (2003) observed that groups of fish treated with TRP expressed lower growth rates and suggested that this could be an effect of increased brain serotonergic activity and decreased aggression and/or appetite. Also treatment of TRP-supplemented feed resulted in depressed growth, increased food consumption and food conversion ratio in juvenile rainbow trout and European sea bass Dicentrarchus labrax (Papoutsoglou et al. 2005a, b). In the present study, feed was offered ad libitum and feed intake was not studied; however, in contrast to previous studies, there was no negative effect of TRP supplementation on the growth of pikeperch post-larvae. Hseu et al. (2003) reported also that feed supplemented with TRP induced decreased size heterogeneity in juvenile grouper which can impact on intensity of cannibalism within a fish cohort. In the presently reported study, TRP treatment had no significant effect on final size heterogeneity in pikeperch post-larvae. The growth rate and size heterogeneity of pikeperch post-larvae here were similar to the ones observed in the previous studies (Szkudlarek and Zakęś 2007; Kestemont et al. 2007; Szczepkowski et al. 2011).

To our knowledge, this is the first study reporting the effect of TRP supplementation on the growth and cannibalism-survival relations in fish post-larvae. In the previous studies, usually TRP effect in juvenile fish was evaluated. In summary, the results of this study showed that dietary supplementation with TRP alters the aggressive behavior of pikeperch post-larvae, and this change in behavior was probably correlated with the 5-HT levels. This effect could be even more pronounced when combined with other methods for decreasing cannibalism, such as optimal stocking densities or size sorting which was not studied here. Moreover, TRP-supplemented diet (5, 10 and $20 \mathrm{~g} \mathrm{TRP} \mathrm{kg}^{-1}$ ) had no negative effect on growth rate of pikeperch post-larvae that suggested further study on optimal time (earlier, 
e.g., at co-feeding procedure) or dose (higher) of TRP treatment. The latter is a result of the fact that the nutritional requirements of percid fish are still unknown and commercial diet dedicated to these species is not available on the market.

Acknowledgments The research was funded by the Polish National Science Centre (Contract No. 5251/B/ P01/2011/40). The authors are grateful to Katarzyna Gromadzka-Hliwa (Polish Academy of Science in Olsztyn) and Marek Hopko (Inland Fisheries Institute in Olsztyn) for technical assistance.

Open Access This article is distributed under the terms of the Creative Commons Attribution 4.0 International License (http://creativecommons.org/licenses/by/4.0/), which permits unrestricted use, distribution, and reproduction in any medium, provided you give appropriate credit to the original author(s) and the source, provide a link to the Creative Commons license, and indicate if changes were made.

\section{References}

Aldegunde M, Soengas JL, Rozas G (2000) Acute effects of L-tryptophan on tryptophan hydroxylation rate in brain regions (hypothalamus and medulla) of rainbow trout. J Exp Zool 286:131-135

Babiak I, Mandiki SNM, Ratsinjomanana K, Kestemont P (2004) Initial weight and its variation in postlarval Eurasian perch affect quantitative characteristics of juvenile cohorts under controlled conditions. Aquaculture 243:263-276

Baras E (2013) Cannibalism in fish larvae: What have we learned? In: Qin JG (ed) Larval fish aquaculture. Nova Science Publishers, New York

Baras E, Jobling M (2002) Dynamics of intracohort cannibalism in cultured fish. Aquac Res 33:461-479

Baras E, Kestemont P, Mélard C (2003) Effect of stocking density on the dynamics of cannibalism in sibling larvae of Perca fluviatilis under controlled conditions. Aquaculture 219:241-255

Cuff WR (1980) Behavioral aspects of cannibalism in larval walleye, Stizostedion vitreum. Can J Zool 58:1504-1507

Czesny SJ, Graeb BDS, Dettmers JM (2005) Ecological consequences of swim bladder noninflation for larval yellow perch. Trans Am Fish Soc 134:1011-1020

De Pedro N, Pinillos ML, Valenciano AI, Alonso-Bedate M, Delgardo MJ (1998) Inhibitory effects of serotonin on feeding behavior in goldfish: involvement of CRF. Peptides 19:505-511

Hamza N, Mhetli M, Kestemont P (2007) Effects of weaning age and diets on ontogeny of digestive activities and structures of pikeperch (Sander lucioperca) larvae. Fish Physiol Biochem 33:121-133

Harlioğlu MM, Harlioğlu AG, Yonar SM, Duran TC (2014) Effects of dietary L-tryptophan on the agonistic behavior, growth, and survival of freshwater crayfish Astacus leptodactylus Eschscholtz. Aquac Int 22:733-748

Hecht T, Appelbaum S (1988) Observations on intraspecific aggression and coeval sibling cannibalism by larval and juvenile Clarias gariepinus (Clariidae: Pisces) under controlled conditions. J Zool 214:21-44

Hecht T, Pienaar GA (1993) A review of cannibalism and its implications in fish larviculture. J World Aquac Soc 24:246-261

Höglund E, Bakke MJ, Øverli Ø, Winberg S, Nilsson GE (2005) Suppression of aggressive behaviour in juvenile Atlantic cod (Gadus morhua) by L-tryptophan supplementation. Aquaculture 249:525-531

Hseu JR, Lu FI, Su HM, Wang LS, Tsai CL, Hwang PP (2003) Effects of exogenous tryptophan on cannibalism, survival and growth in juvenile grouper, Epinephelus coioides. Aquaculture 218:251-263

Jacobs BL, Fornal CA (1991) Activity of brain serotoninergic neurons in the behaving animal. Pharmacol Rev 43:563-578

Johnston WL, Atkinson JL, Hilton JW, Were KE (1990) Effect of dietary tryptophan on plasma and brain tryptophan, brain serotonin, and brain 5-hydroxyindoleacetic acid in rainbow trout. J Nutr Biochem $1: 49-54$

Kestemont P, Mélard C (2000) Aquaculture. In: Craig JF (ed) Percid fishes-systematics, ecology and exploitation. Wiley, Oxford

Kestemont P, Jourdan S, Houbart M, Mélard C, Paspatis M, Fontaine P, Cuvier A, Kentouri M, Baras E (2003) Size heterogeneity, cannibalism and competition in cultured predatory fish larvae: biotic and abiotic influences. Aquaculture 227:333-356 
Kestemont P, Xueliang X, Hamza N, Maboudou J, Imorou Toko I (2007) Effect of weaning age and diet on pikeperch larviculture. Aquaculture 264:197-204

Król J, Flisiak W, Urbanowicz P, Ulikowski D (2014) Growth, cannibalism and survival relations in larvae of European catfish Silurus glanis (Actinopterygii: Siluriformes: Siluridae)—attempts to mitigate sibling cannibalism. Acta Ichthyol Piscat 44(3):191-199

Król J, Dauchot N, Mandiki SNM, van Cutsem P, Kestemont P (2015) Cannibalism in cultured Eurasian perch Perca fluviatilis (Actinopterygii: Perciformes: Percidae)-implication of maternal influence, kinship and sex ratio of progenies. Acta Ichthyol Piscat 45(1):65-73

Kubitza F, Lovshin LL (1999) Formulated diets, feeding strategies and cannibalism during intensive culture of juvenile carnivorous fishes. Rev Fish Sci 7:1-22

Laranja JLQ, Quinitio ET, Catacutan Mae R, Relicardo MC (2010) Effects of dietary L-tryptophan on the agonistic behavior, growth and survival of juvenile mud crab Scylla serrata. Aquaculture 310:84-90

Lepage O, Tottmar O, Winberg S (2002) Elevated dietary intake of L-tryptophan counteracts the stressinduced elevation of plasma cortisol in rainbow trout (Oncorhynchus mykiss). $\mathrm{J}$ Exp Biol 205:3679-3687

Mandiki SNM, Babiak I, Krol J, Rasolo JFR, Kestemont P (2007) How initial predator-prey ratio affects intra-cohort cannibalism and growth in Eurasian perch Perca fluviatis L larvae and juveniles under controlled conditions. Aquaculture 268:149-155

Papoutsoglou SE, Karakatsouli N, Chiras G (2005a) Dietary L-tryptophan and tank colour effects on growth performance of rainbow trout (Oncorhynchus mykiss) juveniles reared in a recirculating water system. Aquac Eng 32:277-284

Papoutsoglou SE, Karakatsouli N, Koustas P (2005b) Effects of dietary L-tryptophan and lighting conditions on growth performance of European sea bass (Dicentrarchus labrax) juveniles reared in a recirculating water system. J Appl Ichthyol 21:520-524

Smith C, Reay P (1991) Cannibalism of teleost fishes. Rev Fish Biol Fish 1:41-64

Szczepkowski M, Zakęś Z, Szczepkowska B, Piotrowska I (2011) Effect of size sorting on the survival, growth and cannibalism in pikeperch (Sander lucioperca L.) larvae during intensive culture in RAS. Czech J Anim Sci 56:483-489

Szkudlarek M, Zakęś Z (2007) Effect of stocking density on survival and growth performance of pikeperch, Sander lucioperca (L.), larvae under controlled conditions. Aquac Int 15:67-81

Teletchea F, Fontaine P (2014) Levels of domestication in fish: implications for the sustainable future of aquaculture. Fish Fish 15:181-195

Winberg S, Øveril Ø, Lepage O (2001) Suppression of aggression in rainbow trout (Oncorhynchus mykiss) by dietary L-tryptophan. J Exp Biol 204:3867-3876

Wolkers CPB, Serra M, Szawka RE, Urbinati EC (2014) The time course of aggressive behaviour in juvenile matrinxã Brycon amazonicus fed with dietary L-tryptophan supplementation. J Fish Biol 84:45-57

Zakęś Z (2007) Out-of-season spawning of cultured pikeperch [Sander lucioperca (L.)]. Aquac Res 38:1419-1427

Zakęś Z, Demska-Zakęś K (2009) Controlled reproduction of pikeperch Sander lucioperca (L.): a review. Arch Pol Fish 17:153-170 